Mujer y Educación. Un largo camino hacia la igualdad

\title{
Cuerpos carnavaleros y deconstrucción del género en el carnaval de Cádiz ${ }^{1}$
}

Carnival bodies and deconstruction of gender in the carnival of Cádiz

\author{
Michael Steven Camelo Gómez \\ Docente - Investigador \\ Secretaria de Educación Distrital \\ michaelcamelo10@gmail.com
}

\section{Resumen}

Este artículo trata de un estudio sociocultural en el abordaje de prácticas discursivas que deconstruyen el género normativo, a través del cuerpo de hombres y su expresión durante carnavales. Su propósito, es explorar la relación entre carnavalización y lenguaje corporal en el Carnaval de Cádiz - España, considerando la creación de personajes en la transgresión de la masculinidad heteronormativa. Bajo un paradigma cualitativo, de estudio etnográfico que resaltó el arte del performance, se trabajó con un Focus Group de personas que fueron entrevistadas y fotografiadas, para demostrar las múltiples expresiones No Binarias del género. El vestuario es una representación del orden patriarcal, los hombres travestidos quiebran reglas condicionantes de masculinidad y feminidad. Ante ello, el travestismo y la teoría queer, contribuyen a la desconstrucción del pensamiento heteronormativo, pues validan todos los lenguajes expresivos del cuerpo.

Palabras clave: Carnaval de Cádiz, Carnavalización, Cuerpo, Teoría Queer, Travestismo.

\section{Abstract}

${ }^{1}$ Recibido: 09/02/2021 Evaluado: 20/02/2021 Aceptado: 13/03/2021 
This article deals about a sociocultural study focus on discursive practices that deconstruct normative gender through men's body and its expression during carnivals. Its purpose is to explore the relationship between carnivalization and body language in the Carnival of Cádiz - Spain, considering the creation of characters in the transgression of heteronormative masculinity. From a qualitative paradigm, an ethnographic study that promoted performance art, were worked with a focus group of people interviewed and photographed to demonstrate the multiple Non-Binary expressions of gender. Clothing is a representation of the patriarchal order, travestism in mes break the conditionated rules of masculinity and femininity. For this reason, transvestism and queer theory, give a contribution to the deconstruction of the heteronormative thinking, due to it's validate all the expressive languages of the body.

Keywords: Cádiz Carnival, Carnivalization, Body, Queer Theory, Transvestism.

\section{Introducción}

En el actual artículo se presentan los resultados del proyecto de investigación Cuerpos Carnavaleros y Deconstrucción del Género en el Carnaval de Cádiz, ejercicio de observación y análisis realizado en la Ciudad de Cádiz, Comunidad Autónoma de Andalucía - España en el año 2020. Se centró en el carnaval de Cádiz porque muestra la transgresión del mundo binario, al retar la representación del vestuario como orden heterosexual establecida. El objetivo principal fue explorar la relación entre carnavalización y lenguaje corporal, considerando la creación de personajes en hombres que transgreden la masculinidad heteronormativa. Se tuvieron en cuenta los aportes teóricos desde tres temáticas: carnaval, cuerpo y género.

El carnaval trasgrede algunas normas sociales -incluyendo las heteronormativas- donde el cuerpo se expresa a partir de posturas no rígidas, en cuanto a los cánones. En consecuencia, se tomó el Carnaval de Cádiz como escenario educativo en la formación de identidades culturales y del género. "El rechazo de los cuerpos por su sexo, sexualidad o color es una «expulsión» de la que se desprende una «repulsión» que establece y refuerza identidades culturalmente hegemónicas " (Butler, 2007, p. 262). Con la participación focal de cinco hombres entrevistados y otros 15 que también estaban disfrazados de mujer, se verifica que las esferas de interrelación no deben orientarse por clasificación de sexo, cultura o del vestir, ya que en la gran diversidad que amplía horizontes, se comprenden todas las maneras de expresarse en el marco del respeto por la vida digna.

El artículo parte de la problemática expuesta en torno a las violencias del género y las posibilidades de expresión en carnavales. Se estructura en cuatro partes, la primera, el Marco Teórico, que expone el aparato conceptual, abordando tres categorías: Carnaval, Cuerpo y Género. En la segunda parte, se explica el paradigma metodológico, tipo de estudio, criterios de selección de la población e interacción. También se explican los instrumentos de recolección utilizados. En la tercera parte, Resultados, se integra lo más representativo de las fases anunciadas, y en la quinta parte, se incluye un apartado de Discusión y Conclusiones que ahondan en reflexiones entre Género y Sociedad. 


\section{Marco Teórico}

Se abordaron tres categorías en el desarrollo teórico y práctico de la propuesta: carnaval desde la concepción de Bajtín, García y Eco; deconstrucción de sexualidades, con las posturas de Butler, Foucault y Preciado. Como complemento, cuerpo y experiencia desde planteamientos de Dewey, Diaz y Ferreiro. Estos referentes se complementan con otras visiones epistemológicas y teóricas que aportan al campo de conocimiento.

\section{Carnaval y Carnavalización}

La carnavalización del mundo se relaciona con un ejercicio de des-jerarquización de ámbitos organizativos estabilizados, es la forma de representar el arte del cuerpo, antepuesto a una sociedad que imputa moralmente cómo moverse. "Se trata de la irrupción de la vida festiva a través de la cual ocurre una fuga del orden vigente, para inaugurar algo así como una segunda existencia, que contradice la congruencia identitaria instituida por las relaciones sociales" (García, 2013, p. 125). Las aportaciones conceptuales que Mijaíl Bajtín (2003) hace sobre carnaval como fenómeno, siguen teniendo fuerza en el contexto cultural actual, ya que irrumpen el tiempo-espacio habitual, que impone el control de mentes y cuerpos. La transgresión no se enmarca en un espectáculo artístico, sino que "está situada en las fronteras entre el arte y la vida. En realidad, es la vida misma, presentada con los elementos característicos del juego" (p. 7). En sus apreciaciones, la diferencia entre actoresespectadores del teatro aristotélico, es infringida, pues el carnaval propone la ciudad como escenario, las personas como actores y la vida como representación, una distinción de la monotonía, donde no se asiste al carnaval sino se "vive, ya que el carnaval está hecho para todo el pueblo" (p. 7).

Es la única fiesta que el pueblo se da a sí mismo, el pueblo no recibe nada, no venera a nadie, él se siente el amo, y únicamente el amo (no hay invitados ni espectadores, todos son amos); en segundo lugar, la multitud es todo menos melancólica: desde que inicia la fiesta, todos abandonan su gravedad (Bajtín, 2003, p. 202).

El carnaval se inició como representación social, "que se manifestaba en las parodias, burlas, irreverencias y sátiras, más o menos divertidas o amargas, de las que eran objeto los altos cargos eclesiásticos. El desquite de los subalternos frente a los poderes" (Prat, 1993, p. 288). La mayoría de los carnavales han sido prohibidos en algún momento por la iglesia o clases dirigentes, pues en sus festividades sobrepasan leyes, así que representan peligro para el sistema. Es una herencia de las saturnales donde "la inversión de papeles que las caracterizaba se acepta como un recuerdo de la edad feliz en la que había abundancia sobre la tierra y que todos los hombres eran iguales, sin distinción entre libres y esclavos" (Prat, 1993, p. 286).

Para Bajtín (2003) en los carnavales se representan el carácter político y social más antiguo de la fiesta popular, "nada de brillantes procesiones ante las cuales el pueblo deba rezar y asombrarse: aquí uno se limita a dar una señal, que anuncia que cada cual puede mostrarse tan loco y extravagante como quiera" (p. 199). Sin embargo, Umberto Eco (1984) manifiesta 
que desde que fue aceptado por las clases superiores, el carnaval se mantiene como excusa para legitimar estructuras de dominación, pues a través de la parodia, las reglas y representaciones cómicas, "se sabe hasta qué grado están prohibidos ciertos comportamientos y se debe sentir el dominio de la norma prohibitiva para apreciar su transgresión. Sin una ley valida que se pueda romper, es imposible el carnaval" (p. 16).

\section{Cuerpo y Experiencia para Transformar-se}

El cuerpo fue el objeto de análisis principal, pues dramatiza y experimenta estados diversos de tiempos, lugares, sexos, hábitos, disciplinas y poderes establecidos. El lenguaje corporal es un acto creador, transforma rutinas, atrae, otorga fuerza y convicción para ser libres colectivamente. "El cuerpo no es una superficie pasiva a la espera de significación, sino un campo político cuyos confines resultan siempre negociables, es un margen peligroso en donde confluyen aperturas y contaminaciones" (Pisano, 2016, p. 725). Sus expresiones estimulan la interacción con el mundo desde gestos, emociones, posturas, actitudes y códigos no verbales, que satisfacen la necesidad de socializar y construir ámbitos de convivencia.

"Los cuerpos sólo surgen, sólo perduran, sólo viven dentro de las limitaciones productivas de ciertos esquemas reguladores" (Butler, 1993, p. 14). Hay algunos que por sus condiciones físicas o de expresión del género, contraria con estereotipos, son clasificados y desterrados por el sistema opresor. Sin embargo, hay estudios y millares personas que transgreden límites del tabú, el binarismo, el sometimiento y el silencio. La manera de liberar cuerpos es a través de la experiencia, que dimensiona "la interacción del organismo con su ambiente humano, así como también físico, la tradición, instituciones y circunstancias locales (Dewey, 2008, p. 278).

Butler (2007) sitúa el carácter del cuerpo multiforme, sin regulaciones políticas ni jerarquías, así que interroga lenguajes significativos en la realización corporal del género, "un estilo corporal, un «acto», por así decirlo, al mismo tiempo intencional y performativo" (Butler, 2007, p. 271). La utilización de máscaras y disfraces en celebraciones, el cambio de posturas, hombres travestidos y ritos de origen pagano, "se han interpretado en la existencia del Carnaval en cualquier cultura que ha precedido. $\mathrm{Y}$ así se recuerdan los orígenes remotísimos que podrían suponer las bacanales, las saturnales y las lupercales, fiestas en honor a los dioses Baco, Saturno y Pan" (Bajtín, 2003, p. 09). La heterosexualidad forzada se presenta como verdadera, pero niega la autenticidad de la persona en esferas sexuales, estéticas y sociales en búsqueda de escenarios para vivir en paz.

Al ser impuesto un sexo, el cuerpo hereda normas para actuar en la sociedad de consumo, el vestuario adquiere un significado de orden establecido social y del género. De esta forma, los estereotipos son adquiridos en la formación cultural, creando imaginarios sobre el hombre varonil o la mujer femenina aceptados, así se limitan posibilidades alternas de expresión. Según Butler (1993) la lógica neoliberal reproduce la linealidad de asumir un sexo "con la cuestión de la identificación y con medios discursivos que emplean el imperativo heterosexual para permitir ciertas identificaciones y repudiar otras" (p.19). Estas son adheridas en mentalidades comunes que enjuician a quienes viven distinto. "La libertad, la posibilidad y la capacidad de acción se establecen desde un espacio fundado en relaciones de poder" (Fonseca y Quintero, 2009, p. 53). 
La masculinidad asocia un hombre estereotipado que sigue conductas agresivas, un sujeto dominante que cumple trabajos duros y es insensible a emociones frágiles. Patrones promovidos por medios publicitarios, que rechazan y sesgan, pues la mayoría no cumple estos modelos. Sin embargo, otros se niegan a hacerlo, cuerpos disidentes de una masculinidad hegemónica, "que asegura lo masculino como una especie de pánico de llegar a afeminarse" (Butler, 1993, p. 19). En los carnavales de Cádiz, el actor ata su experiencia con el performance, pues asume su personaje para expresar cualidades físicas y mentales fuera de la esfera rígida para reinventarse otro "yo". "El proceso vivido en una actuación constituye una retrospección creativa, durante el cual los eventos y partes de una experiencia se resignifican" (Ferreiro, 2012, p. 11).

\section{Deconstrucción de lenguajes Heteronormativos}

El género dominante lo atribuyen herencias sociales que asignan a los cuerpos patrones sexuales sobre cómo comportarse para ser admitidos; así condicionan planos binarios para alcanzar exigencias morales religiosas, negando las realidades de exploración corporal y emocional. Ante ello, Butler (en Fonseca y Quintero, 2009) plantea, que la construcción de identidad es “imitativa, ya que los roles de género no son más que una representación teatral donde cada sexo asume los papeles creados con anterioridad, imitando y reproduciendo continuamente" (p. 45).

La herencia de conductas discriminadoras ha generado violencias de género, al situar prácticas sexuales como indeseables $\mathrm{y}$, por tanto, relegar, marginar y catalogar como desviados a aquellos individuos que se alejan de la norma social (Pérez, 2014, p. 17). La Teoría Queer resignifica derechos sexuales de personas que exigen libertad y autodeterminación para existir desde placeres subjetivos, ha sido "un término que nunca fue poseído plenamente, sino que siempre y únicamente se retoma, se tuerce, se "desvía" de un uso anterior y se orienta hacia propósitos políticos apremiantes y expansivos" (Butler, 1993, p. 320). La deconstrucción de posturas y discursos, generan extensión en el alcance de lo queer, resaltando la diversidad y disminuyendo las relaciones de poder. "La única forma de crear una sociedad igualitaria en género es precisamente, excluir esta categoría como unidad de análisis, permitiendo que el género se desdibuje en uno solo, el género humano" (Pérez, 2014, p. 17).

La teoría queer resalta posibilidades promoviendo la "destrucción de las identidades gay, lésbica, transexual, travestí, e incluso la hetero, para englobarlas en un "totalizador" mundo raro, subversivo y transgresor, que promueve un cambio social y colectivo desde muy diferentes instancias en contra de toda condena" (Fonseca y Quintero, 2009, p. 56). Así, se abren debates íntegros que disminuyen escenarios de discriminación, "ser queer no significa combatir por un derecho a la intimidad, sino por la libertad pública de ser quién se es, cada día, en contra de la opresión: la homofobia, el racismo, la misoginia, la intolerancia de los hipócritas religiosos y de nuestro propio odio" (p. 56).

En las posibilidades que brinda la teoría queer, se expresa el travestismo como modo de apropiación y representación de género. Los travestis son personas que por un período de tiempo visten, maquillan y actúan como el sexo opuesto, generalmente para fiestas o espectáculos, "cuando se trata de hombres vestidos y maquillados como mujeres, lo que se da es la desestabilización del género mismo, que ha sido desnaturalizada y que pone en tela de juicio las pretensiones de normatividad" (Butler, 1993, p. 188). Este colectivo sufre 
señalamientos médicos, psicológicos y psiquiátricos por usar ropa distinta a la reglamentaria, dejando entrever normas que determinan los derechos humanos como la libertad de expresión, el desarrollo de la libre personalidad y los derechos sexuales.

El travestismo asume la estructura imitativa impuesta, pues al vestir del género contrario, usan elementos de consumo que clasifica lo femenino o varonil, ante ello, cuando se acerca más a la teoría queer, se eliminan las normas sobre cómo vestirse, ya que no hay género propio del varón, ni uno que pertenece a las mujeres. El género es consecuencia de un sistema que se apropia de valores culturales de los sexos. Validando esta teoría, se trastoca "la exigencia médico-legal de que un sexo va unido a la exigencia de una determinada sexualidad" (González, 2009, p. 238) donde se señala a personas por vestir diferente, negando la realidad de que "no sólo hay muchos heterosexuales que practican el travestismo, sino que además sería un error pensar que la mejor manera de explicar la homosexualidad es a través de éste" (Butler, 1993, p. 330).

Cualquier etiqueta a personas por su expresión sexual, es obsoleta, pues las identidades no son fijas, por ello la teoría queer y el travestismo reconocen todas las formas de expresión corporal como válidas. En carnavales, los cuerpos transforman la norma estereotipada del lenguaje, así que ponen en escena figuras que superan la mirada heterosexual, cuerpos abiertos a re-existir. Un hombre disfrazado de mujer, supone un desafío a categorías estéticas de comportamiento masculino o femenino, que pierden sentido en realidades heterogéneas del ser mujer u hombre más allá de la ropa.

\section{Metodología}

La propuesta está enmarcada en el Paradigma de Investigación Cualitativa, que profundizó en las miradas y percepciones de personas que interactúan allí. El Enfoque Hermenéutico, se sustenta en la descripción, comprensión e interpretación de estudios socio-culturales, en la transgresión del sistema homogéneo. Se adecuó un tipo de estudio Etnográfico, que resaltó el arte del performance. Así, se diseñaron diversas técnicas e instrumentos de recolección de información, que contribuyeron a "descubrir aquellas ataduras de esclavitud de las que somos todos víctimas más o menos inconscientes, buscar entonces liberar" (Vasco, 1994, p. 22).

La población objeto de estudio aportó lenguajes desde la teoría de la carnavalización, en la creación de personajes histórico-sociales con experiencias, memorias, sentimientos, atravesados por la sexualidad, el género, la etnia, la clase social, entre otras configuraciones culturales que impregnan aún con altos grados de injusticia. Los participantes se dividieron en tres grupos, con el fin de organizar la información y cumplir los objetivos. A. Cuatro personas que brindaron percepciones previas sobre el carnaval (Entrev-a); B. Cinco disfrazadas que fueron fotografiadas y entrevistadas en el escenario callejero (Entrev-b), cuatro de ellas se autodenominaron heterosexuales y 1 no binario; y C. Quince más fotografiadas con su personaje. Las fotografias son el "elemento del que disponemos para apoyar nuestras preguntas, hipótesis y respuestas” (Gómez, 2013, p, 347). 
Figuras 1 y 2. Masculinidades Disidentes en Carnaval.
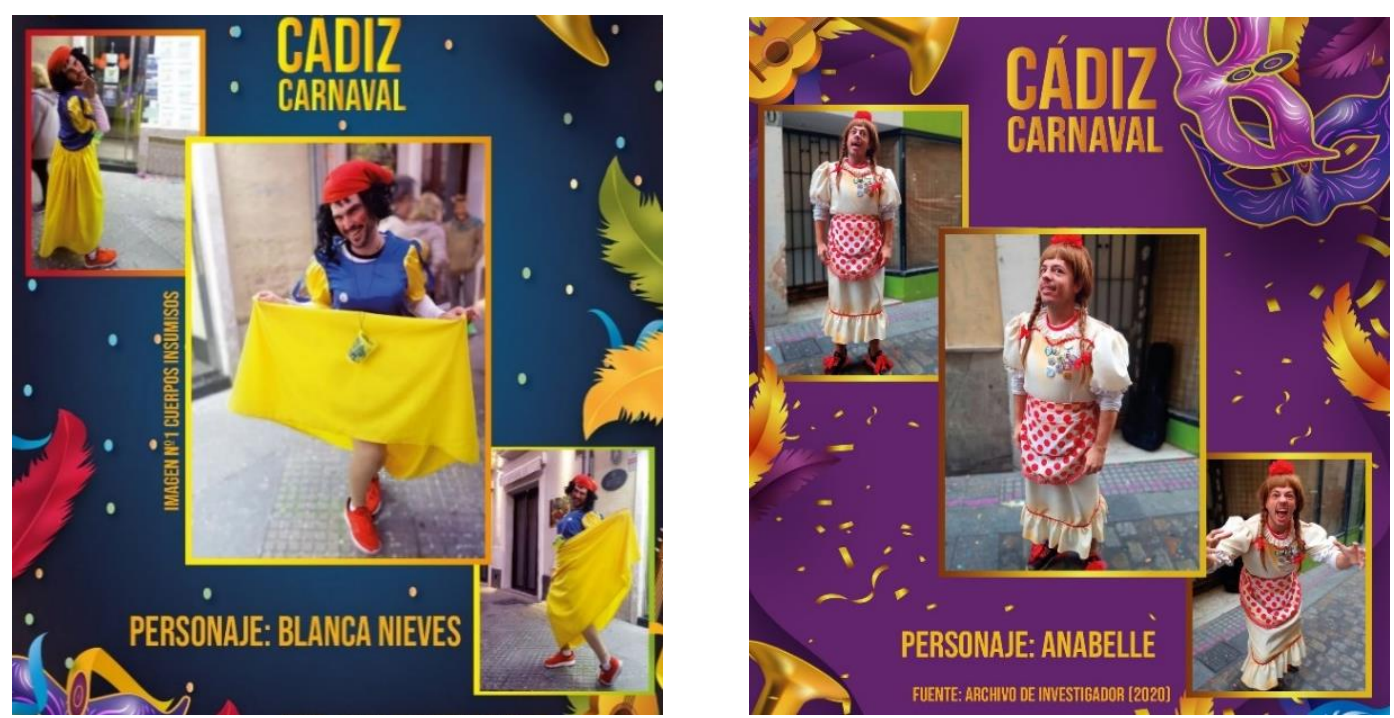

Fuente: Archivo Personal del Investigador. Carnaval de Cádiz, Cádiz - España. Febrero 2020.

La etnografía de la deconstrucción de sexualidades tomó las fotos como "forma de registro de prácticas sociales, rituales y normas que rigen ciertos escenarios culturales" (De alba, 2010, p. 58). En el análisis de la fotografía se tuvo en cuenta la descripción de personajes, sus posturas, ropas, maquillaje, movimientos y poses que dejan entrever creaciones artísticas en resistencia. Para posicionar la estética popular en las imágenes y adecuarlas para su interpretación, se resaltaron sus contrastes, brillos, sombras y perspectiva, por medio del programa Photoshop 2019. Siendo así, se creó la galería fotográfica "Cuerpos Insumisos en Carnaval", que expone 20 personas con sus creaciones artísticas.

\section{Construyendo información}

Las técnicas de recolección de información consistieron en: Observación Participante, Fotografías y Entrevistas Etnográficas. Asimismo, corresponden instrumentos: notas de campo, formato de pregunta semiestructurada y sistema de categorías.

\section{Técnica: La Observación Participante}

Fue continua para comprender las características de la carnavalización bajtiniana, donde la extensión espacial, se limitó a escenarios callejeros: plazas, parques, mercado y calles, dimensionando el impacto popular que tiene este evento en la cultura gaditana. Los tiempos se fijaron en 7 días del carnaval 2020, entre las 14 pm y las 20 pm, ya que después de esta franja la mayoría entraba en un estado de alicoramiento y las personas se aglomeraban en los escenarios, dificultando la interacción para grabar. Se hizo un ejercicio de observación 
focalizada, que consiste en fijarse en aspectos concretos, participando de manera activa, donde "el etnógrafo interactúa de manera normal y espontánea con otros participantes, llegando inclusive a hacer parte de los grupos que integran (Peralta, 2009, p. 47). La observación participante fue abordada con la escritura de notas de campo, que eternizaron la información para su posterior transcripción y análisis.

\section{Técnica: Entrevistas Etnográficas}

En la investigación se realizaron nueve entrevistas etnográficas (cuatro previas al carnaval a las que se les denomina "Entrev-a"; y cinco a personas disfrazadas durante carnaval referenciadas como "Entrev-b"), que permitieron obtener los resultados. Se usó un guión en entrevistas semiestructuradas, para que el investigador fuera "libre de formular las preguntas de manera conveniente, tratando los mismos temas con todos los entrevistados" (Bonilla y Rodríguez, 1995, p. 96). Para ello se usó una grabadora de audio, con el fín de perpetrar estáticamente la información y tener mayor tiempo para su transcripción e interpretación. "Es luego, al estudiar la transcripción, cuando se analiza cada expresión, argumento, figura o comentario del informante" (Sanmartín, 2000, p. 122). Las entrevistas se contrastaron con datos hallados en fuentes bibliográficas, que permitieron ampliar el corpus argumentativo.

\section{Técnica: Fotografía}

Fueron 20 personas fotografiadas que permitieron la obtención de información, al posar ante la cámara de manera espontánea y representar el personaje creado. "A través de la fotografía se hacen visibles determinadas partes de la experiencia que son difíciles de ser expresadas a través de la palabra" (González, 2008, p. 06). Para el análisis de las fotografías, se usó la interpretación de cuatro categorías macro: Creación de personajes, Expresión, Teatralización y Rigidez Heteronormativa.

Figura 3. Categorías de Análisis de Personajes

\begin{tabular}{|c|c|c|c|c|c|c|c|}
\hline \multirow{4}{*}{ 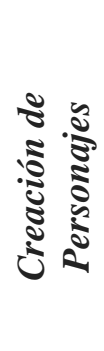 } & Vestuario & \multirow{4}{*}{$\frac{\sqrt[0]{0}}{\stackrel{0}{\frac{0}{2}}}$} & Gestualidad & \multicolumn{2}{|r|}{ Improvisación } & \multicolumn{2}{|r|}{ Tensión } \\
\hline & Maquillaje & & $\begin{array}{l}\text { Repetición } \\
\text { performática }\end{array}$ & 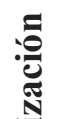 & $\begin{array}{l}\text { Apropiación del } \\
\text { personaje }\end{array}$ & త & $\begin{array}{l}\text { muscular } \\
\text { Pose }\end{array}$ \\
\hline & $\begin{array}{c}\text { Nombre del } \\
\text { personaje }\end{array}$ & & Relación & 氕 & $\begin{array}{l}\text { Lectura socio- } \\
\text { histórica }\end{array}$ & 気 & Actitud \\
\hline & $\begin{array}{l}\text { Elementos } \\
\text { simbólicos }\end{array}$ & & social & $\Leftrightarrow$ & Voz & Е & Movimiento \\
\hline
\end{tabular}

Fuente: Elaboración Propia.

\section{Resultados}

El carnaval vislumbra los elementos de carnavalización como características colectivas del unir del pueblo, que durante algunos días quebranta, normas sociales. Los escenarios que más los reúnen, están situados en lugares públicos comunes y gratuitos: plazas, calles, barrios, mercado central y peñas, una contraposición contra el régimen que privatiza espacios y limita movimientos. Es un encuentro donde la música, los disfraces y algunos excesos como la bebida, hacen parte del estado corporal que libera. Para definir las características de la carnavalización en el Carnaval de Cádiz, se toman ocho elementos que Bajtín (2003) destaca 
en su obra en el contexto del renacimiento y que siguen teniendo vigencia socio-cultural en la actualidad.

Libertad, Poder y Transgresión: El carnaval vulnera rutinas de espacios, tiempos y formas de comportarse para ser admitido socialmente. La transgresión se dimensiona en esferas que desafían la moral religiosa, al disfrazarse de cualquier género o especie del ser vivo, al encontrarse fuera del espacio privado que se perpetua diariamente.

Teatralidad: Todo el carnaval es un teatro en la calle, los personajes, los eventos simultáneos, los tonos y movimientos de artistas. La teatralidad está basada en la trasgresión de cuerpos dóciles y rígidos, víctimas de la globalización y la historia de las guerras. Es "la naturaleza de la exageración, que tiende perpetuamente a rebasar todos los límites, sean cuales sean; llevado el autor grotesco por su pasión y por su misma embriaguez" (Bajtín. 2003, p. 251).

Disfraz y Máscara: En Cádiz son muy comunes los disfraces del género opuesto y por ello, es el centro de esta investigación. En cuanto a la máscara, no se usan las que cubren todo el rostro, pues causan dificultad para cantar y proyectar la voz, así que, se usan antifaces o mascarillas, "que regularmente suelen cubrir desde la frente hasta el labio superior" (Montiel, A. 2010), de esta manera se mantiene la esencia del canto que encubre de magia todo el carnaval.

Vocabulario: El carnaval de Cádiz es muy charlatán donde los mensajes con el uso de eufemismos o palabras grotescas, refieren temas tabúes y atrevidos que tiznan de risa y diversión. "El lenguaje familiar de la plaza pública se caracteriza por el uso frecuente de groserías, o sea de expresiones y palabras injuriosas, a veces muy largas y complicadas" (Bajtín, 1990, p. 21).

La Risa: Todo es más alegre, el humor carnavalesco es festivo, de celebración con el pueblo porque se transforman las dichas y dolores en fiesta. Todo es cómico, grotesco, lleno de alboroto, gritos, burlas, sarcasmos hasta con el mismo cuerpo que rompe cánones de belleza.

Banquete: La bebida y la comida, con su "tendencia a la abundancia se constituye como fundamento de la imagen del banquete popular” (Bajtín, 2003, p. 237). En el carnaval hay tres fiestas gastronómicas, que son "las hostionada, erizada y pestiñada, en cada una de ellas se come un plato típico de Cádiz. La pestiñada es un dulce típico, la erizada que es un tipo de marisco y la hostionada que son ostras" (Entrev. a1. Comunicación personal, 18 de febrero del 2020).

Música: Es una característica común que distingue todos los carnavales del mundo. "La música en el Carnaval de Cádiz es todo, es que realmente es todo, sin música no hay carnaval” (Entrev. a1. Comunicación personal, 18 de febrero del 2020).

Fiesta y Cultura Popular: En este periodo de tiempo, la cultura popular se vive a flor de piel en todos los rincones de la ciudad, donde las expresiones etnográficas, hacen que el gaditano y la gaditana manifiesten "conocimientos, creencias, artes, la moral, las leyes, costumbres y otras aptitudes y hábitos adquiridos como miembros de la sociedad” (Fernández, 2016, p. 20).

Los elementos de carnavalización que se expresan durante los días de carnaval, ayudan a comprender el sentido de cultura popular se manifiesta en el evento gaditano. Sus 
expresiones son de tal riqueza, que mantiene vivo el legado histórico, la memoria, la acción y enunciación de un carnaval que ha sido prohibido, censurado y castigado por regímenes como el de Primo de Rivera (1923 - 1930) o Franco (1939 - 1975). Aun así, el carnaval ha resistido y sigue siendo canal de protesta ante las desigualdades del sistema. Es un evento que reivindica los excluidos, donde la imagen, la palabra y la representación, crean un estilo popular de vida más libre.

\section{Cuerpos y Creación Performática}

Figura 4 y 5. Masculinidades Disidentes en Carnaval.
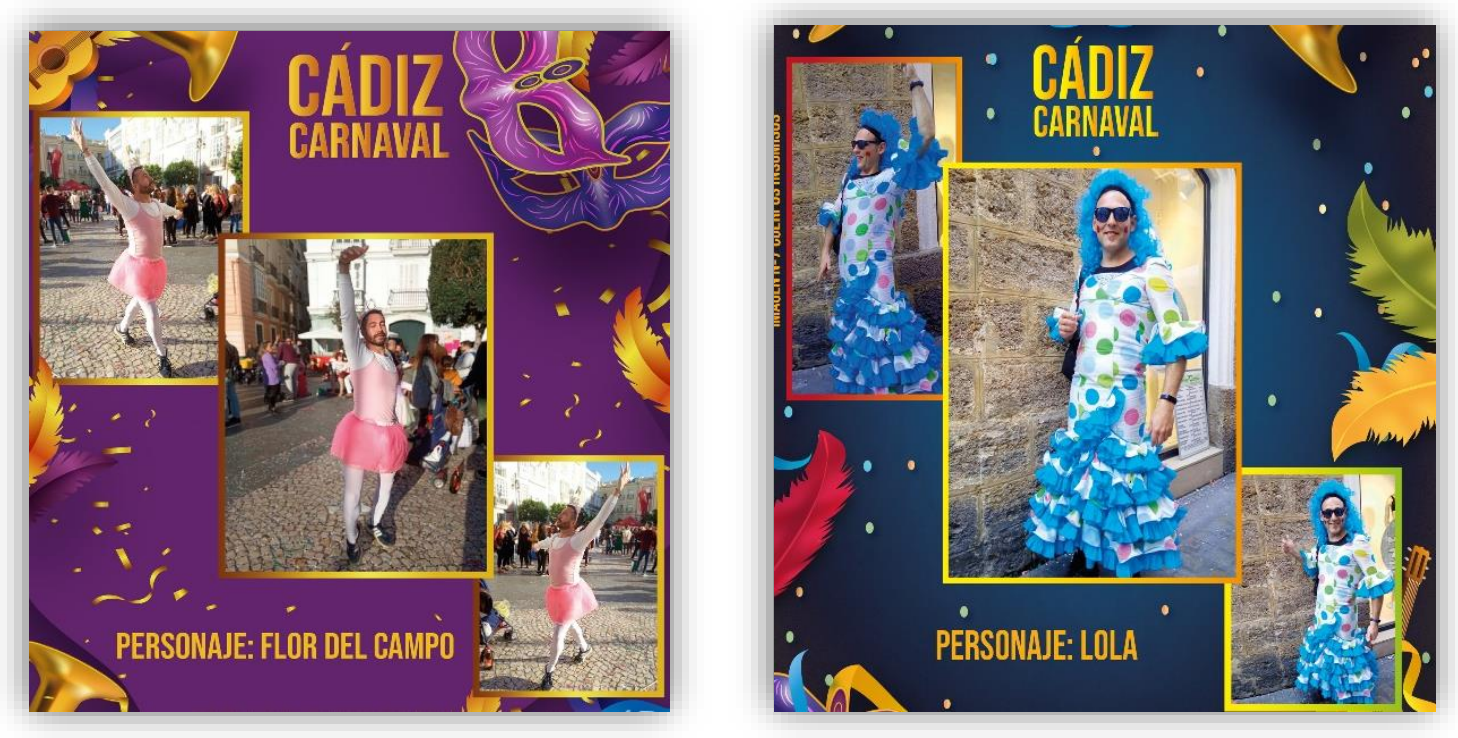

Fuente: Archivo Personal del Investigador. Carnaval de Cádiz, Cádiz - España. Febrero 2020.

"La ropa es un lenguaje y el cuerpo vestido es un territorio físico-cultural en el que se realiza la performance" (Libera, 2016, p. 724). Para la dramatización teatral, las personas usan desde elementos sencillos como pelucas, máscaras, capas, maquillaje básico, hasta disfraces que tienen mucho trabajo de elaboración; "el travestismo es una de las prácticas más comunes del período carnavalesco. Tal carnalidad se asocia con actos opuestos al espíritu cristiano, que transportan al individuo hacia un estado de feliz abandono" (Mastriano, 2013, p. 47). Al resaltar un escenario que sobrepasa fronteras del género, en este caso, a través del travestismo artístico de hombres, se ataca el modelo heteronormativo que impone una única visión del ser hombre o mujer.

El vestuario fotografiado es muy colorido, diverso como las formas de concepción del mundo, de expresión y pretensiones de vida, no importa si es hombre o mujer, todos sueñan. "Es decir, el maquillaje y la ropa visualmente es lo que hace decir, " hostia, guay!". Muchos detalles, muchos motivos que cuando indagas dices wauu que creatividad" (Entrev. a1. Comunicación Personal, 18 de febrero 2020). La gestualidad y emociones se asocian, en su mayoría, a la felicidad, el goce, el movimiento constante, la broma, la elocuencia. Lo anterior tiene relación con lo dicho por una maquilladora profesional en una entrevista previa al carnaval, "al vestirte del otro género, pues tu comportamiento resulta gracioso 
porque intentas actuar en lo que te prohíben día a día. Dejas de ser por un día al año para asumirse como otro" (Entrev. a2. Comunicación personal. 15 febrero 2020).

\section{Estereotipos y Violencia de Género}

La reproducción de estereotipos provoca que, dentro de las relaciones sociales, se represente la exclusión de aquellas que no se adaptan a estos estándares y así mismo, se implanta una idea de mujer u hombre que realmente no existen en general.

Las creencias y expectativas que conforman los estereotipos sociales de género incluyen: rasgos de personalidad (subordinación/dominio), roles (cuidadora/sustentador económico de la familia), profesiones (secretaria/empresario), mandatos (subordinarse a las necesidades de los hombres/demostrar siempre potencia y creer que su cuerpo es una máquina invencible), exigencias sociales (silenciar la propia fortaleza e inteligencia/ocultar las debilidades). En resumen, la feminidad se identifica con subordinación, entrega, pasividad y seducción, mientras que la masculinidad presupone poder, propiedad y potencia (Pla, Donat y Díaz, 2013, p.23)

La transformación de posturas de los 20 hombres al imitar el género, hacen que se devalúe la obligación de actuar "varonil" para agradar dentro del sistema patriarcal. La masculinidad es no ser o al menos no parecer femenino (Segarra y Carabí, 2000; Subirats, 2007, entre otras). Ante ello, la teoría queer amplía los campos del género, en lo cual "es importante comprender las diferentes experiencias de estereotipación del género, porque ayudan a liberar propios condicionamientos socio-culturales" (Cook y Cusack, 2009, p. 236). Sin embargo, aún se reproducen esquemas heredados de la cultura hegemónica, que niegan la normalización de lo natural y lo vuelven tema tabú. Muestra de ello, es que al entrevistar a los sujetos con la pregunta de ¿en qué otros espacios volverías a vestirte del personaje?, tres de ellos respondieron:

- Entrev. b1: En fiestas de disfraces de tipo privado y eso

- Entrev. b2: A una fiesta de Darg Queen o algo así (se ríe). Normalmente no puedo usarlo. Para ciertas ocasiones creo que sí significa expresión para identificarte en un día con algo diferente a lo que no eres y con quienes no les va a importar realmente como te vestiste

- Entrev. b3: Yo creo que solo en carnaval o fiestas de disfraces porque no es muy normativo. En plan si voy a cualquier sitio, te van a decir, iqué haces cojones!

(Comunicación Personal, 27 - 29 de febrero 2020).

En todas las respuestas se interpreta que existe una circunstancia para transformar vestuarios, posturas, movimientos... es carnaval. La vida cotidiana genera algunos temores o riesgos de enfrentar condiciones que el sistema impone para moverse y expresar. El terror homofóbico, es en realidad, "un terror a perder el propio género y a no volver a ser una mujer o un hombre de verdad" (Fonseca y Quintero, 2009. p. 54). Se han alienado tanto las mentes, que hasta el uso de cierta ropa es prohibido, limitando la expresión del género sin tener en cuenta las nuevas formas de entender la masculinidad y las relaciones entre personas no dogmáticas. "Se necesita acceder a las vivencias masculinas, a la experiencia de un cambio que afecta de una manera u otra a su identidad como varones y conocer cómo se enfrentan las diferentes generaciones de hombres a este proceso" (Sanfélix, 2012. p. 223). Por ello mismo, es que la transgresión se da en escenarios de fiesta, pues allí, las personas entran en un estado de carnavalización, que como se ha afirmado hasta ahora, es propicio para transformar. "Sí, es una forma de salirse un poco del tiempo, la normalidad, de lo 
general del día a día y sí. Es como una brecha realmente de rebeldía (Entrev. b2. Comunicación Personal, 29 de febrero 2020).

Las violencias de género se enfocan, al discriminar a seres humanos por no adaptarse a las lógicas binarias, sea por tener más de un órgano sexual, travestirse, ser transexual, gay, lesbiana, bisexual, entre otras categorías que siguen enmarcando para sesgar y dividir. Ser normal, para personas pertenecientes a las minorías del género, es con frecuencia una mera aspiración: llegar a ser normal. Butler ya identificaba la necesidad (1993) de eliminar esos estados que producen misoginia y misandria. Se resalta la imitación para burlar patrones que excluyen y condenan, pero al mismo tiempo deben existir grados de conciencia crítica, sobre los puntos en que se siguen reproduciendo lógicas de violencia, que aún limitan a personas para expresarse libremente. Un ejemplo de ello, son las respuestas a la pregunta ¿Qué sensaciones y emociones has sentido al ir caminando con tu personaje?,

- Entrev. b3: He tenido una experiencia muy buena. Tú te pones y te disfrazas como quieras y nadie dice algo sobre cómo estas. Todo el mundo está aceptándote tal cual estás.

- Entrev. b4: Nervios, porque pensé y si se burlan o no les gusta, pero cuando salí a la calle, ya asumí, voy a ser yo. Es uno de los días en que todo el mundo está alegre y nadie te está diciendo en la calle “¡maricón, gay!” Sabes, todo el mundo cree que es cachondeo y todo el mundo es libre.

- Entrev. b5: Mucha excitación. Pues es un espacio donde la gente no te va a mirar mal hagas lo que hagas porque esto es carnaval. Lo demás será el resto del año, pero ahora es carnaval.

\section{(Comunicación Personal, 27 - 29 de febrero 2020)}

En sus discursos, se reconoce la alegría de poder expresar como quieran desde sus cuerpos $\mathrm{y}$ no ser señalados. Al mismo tiempo evidencian miedos de que fueran reconocidos y tildados, abucheados y tratados mal por las personas que reproducen discursos homofóbicos. "Interesa la manera de cómo se construye la masculinidad en el terreno social y cuáles son las características que la definen para poder analizar la ruptura y sus consecuentes derivados a partir de una identidad masculina rígida y cerrada" (Sanfélix, 2012. p. 229). Ellos reconocen que en la cotidianidad -sin fiesta- sería diferente, pues un hombre no debe liberar su cuerpo de la rigidez varonil como ellos lo han hecho, serían excluidos. "Los géneros no pueden ser ni verdaderos ni falsos, ni reales ni aparentes, ni originales ni derivados." (Butler, 2017, p. 275).

En el Carnaval de Cádiz del año 2017, se registró un hecho de violencia de género, a grande escala. Un joven de 23 años, que hacía parte del coro "La reina de la noche", fue agredido en la calle por ir vestido de Drag Queen. Él narra lo sucedido en el periódico La voz del carnaval,

Me gritó "maricón de mierda", si supiera que era del coro, no creo que se hubiera fijado en mí, afirma el joven, que acto seguido recibió un puñetazo en la cara. Afortunadamente, el joven estuvo rápido $\mathrm{y}$, tras dejar la guitarra en el suelo, consiguió apartar al agresor, lo que le permitió escapar. No hubo más palabras, simplemente el insulto y el puñetazo. No sé ni siquiera si iba bebido, porque solo se dirigió a mí con esas dos palabras (La voz del carnaval, 03 de marzo 2017).

Quienes transgreden la norma, tienen una visión distinta de lo que es vestir y comportarse como mujer u hombre. Las masculinidades hegemónicas definen formas exitosas del ser 
hombre y señala otros estilos masculinos como inferiores. Estas serían las "variantes subordinadas" (Carrigan, Connell y Lee, 1987). El negar la posibilidad a una persona de expresarse como quiera, es legitimar este tipo de hechos, que ocurren cotidianamente en el mundo. En carnaval se transgreden las normas del género, pero en la vida normal es más desafiante, pues muchas personas han sido víctimas fatales por agresiones físicas y psicológicas, producidas por quienes aún no están educados para la diversidad de expresión y pluralidad de sentidos de vida. "Entre más puntos de vista seamos capaces de tener en cuenta, será menos probable que nos quedemos encerrados en una sola perspectiva de las cosas" (Cook y Cusack, 2009, p. 238).

La interacción con las personas entrevistadas y fotografiadas, y el ejercicio de observación participante, permite un reconocimiento de la libre expresión, que en la historia universal, ha sido censurada, condenada y ha ocasionado diferentes puntos de declives con masacres, guerras y conflictos internos. En las respuestas de cuatro personas entrevistadas, resaltan el carnaval para que ciudadanos manifiesten posturas de la sociedad de manera libre, se encuentran en reclamaciones y propuestas para construir identidades culturales.

Figura 6. Fragmento de entrevistas en Carnaval

\begin{tabular}{|l|l|}
\hline $\begin{array}{l}\text { Entrev. b2: Carnaval para mi pues es una } \\
\text { expresión de sentimientos y una crítica a lo } \\
\text { que es la sociedad hoy en día. Tú puedes } \\
\text { expresar y para bien o para mal, lo que nos } \\
\text { rodea hoy en día a nivel social, político y } \\
\text { digamos también en cualquier ámbito. }\end{array}$ & $\begin{array}{l}\text { Entrev. b3: Nuestra sociedad tiene pocas } \\
\text { posibilidades para salir del marco } \\
\text { normativo, de expresarte con tu cuerpo de } \\
\text { manera diferente y pues en carnavales al } \\
\text { ponerme el disfraz, fue una idea súper } \\
\text { buena porque me he sentido súper } \\
\text { liberado. }\end{array}$ \\
\hline $\begin{array}{l}\text { Entrev. a3: Hombre, el carnaval a parte de } \\
\text { la fiesta, es la imagen de mi ciudad. Una } \\
\text { manera de criticar las cosas porque Cádiz } \\
\text { es la cuna de la libertad, es una forma de } \\
\text { quejarse de forma elegante. Explicar qué } \\
\text { no está bien de manera crítica. }\end{array}$ & $\begin{array}{l}\text { Entrev. a4: Bueno, para mi principalmente } \\
\text { es unobby, un medio de desconectar, yo } \\
\text { trabajo, mi familia. Por ejemplo, nosotros } \\
\text { este año hemos cantado un paso doble } \\
\text { defendiendo los derechos de las mujeres. }\end{array}$ \\
\hline
\end{tabular}

(Comunicación Personal, febrero 2020)

En esta lectura, también se confirma el derecho de la equidad sexual, pues el carnaval vence los obstáculos para que todos compartan de manera equitativa. Por ejemplo, parte de las ganancias feministas ha sido el triunfo que "poco a poco va incrementando la intervención de la mujer en el carnaval y en todos los grupos, aunque debería hacerse cada vez más masivo" (Entrev. a4. Comunicación Personal, 1 de febrero 2020). Todas las personas son aceptadas para festejar la vida en estados carnavaleros. Es otorgar el "lugar a prácticas sexuales minoritarias para acabar con el binarismo del género, desestabilizarlo y cuestionarlo como categoría válida de análisis, eliminando la idea de la heterosexualidad natural" (Pérez, 2014, p. 14).

La sexualidad es definitiva en la construcción de una sociedad más igualitaria, con menos índices de violencias de género y con masculinidades más cómodas consigo mismas. La interacción con hombres travestidos amplia la visión de estereotipos sociales del género, 
que se necesitan de construir, para proteger a todas las personas en el fomento de sus derechos humanos vitales. Para ello, se considera fundamental promover una "educación liberadora y crítica, que se complemente y dé cabida a una pedagogía queer" (Carrera, 2016, p.04). Los encuentros con personas en estados de carnavalización, posicionó lenguajes a través de posturas y voces, cada vez menos normativas y más liberadas en la dignificación de vidas.

\section{Discusión y Conclusiones}

La crítica feminista a nivel mundial, orientó el sistema de género como estructura social opresiva, por ello investigaciones de Shirley Chisholm (1970), Petra Kelly (1984), Oyèrónkẹ Oyěwùmí (1997), Rigoberta Menchu (2002), Emily Greene (2003), Sonia Parela (2003), María Lugones (2008), Ellen Jhonson (2011), Rita Segato (2017), entre otras, lograron ganancias históricas, pues se convierten en "la base de todas las prácticas de deconstrucción del género y de los discursos que siguieron su estela" (Lauteris, 2015, p. 114). Con esta base se han consolidado movimientos que claman igualdad en los Derechos Humanos Universales. Butler (2007) plantea que el género no es una identidad establecida, sino más bien "formada en el tiempo, instaurada en un espacio exterior mediante una reiteración de actos" (p. 273).

Las críticas a la hegemonía heteropatriarcal han ampliado miradas, organizando colectivos para exigir libertad de expresión y respeto por la diversidad, pues "no es nada nuevo afirmar que las identidades subalternas que transgreden la norma de género sufren violencia de género" (Carrera, Fernández y Rodríguez, 2013, p. 68). El Manifiesto Contrasexual de Preciado (2001) plantea que, las normas han sido inscritas como verdades biológicas, así que hay que sustituir ese contrato social por uno contrasexual, que proclame la equivalencia de todos los sujetos comprometidos en la búsqueda del placer-saber, donde los cuerpos se reconozcan "no como hombres o mujeres sino como cuerpos hablantes que reconocen a los otros como cuerpos hablantes" (p. 42). Es por ello, que las categorías binarias de sexo, género e identidad sexual están quedando obsoletas, pues sus grados de discriminación niegan lo real.

Lo queer se plantea en torno a la necesidad de pensar el mundo más allá del rígido binomio hombre masculino -heterosexual- mujer femenina, rompiendo la imposición de una identidad unitaria, fija y coherente (Carrera, 2016). La necesaria mirada para ampliar focos incluyentes sin clasificar, condicionar y estereotipar, da como origen la teoría queer, que se asocia inicialmente a la homosexualidad como estigma y gracias a la "liberación gay de la década de 1970, se convirtió en una palabra de orgullo y en un signo de resistencia política. Al igual que las palabras gay y lesbiana, queer ha designado, en primer lugar, una protesta social, y sólo en segundo lugar una identidad personal" (Lauretis, 2015, p. 107).

Se resalta el travestismo como posibilidad de transgredir las normas de género, un "modo de poner en evidencia la incapacidad de los regímenes heterosexuales para legislar o contener por completo sus propios ideales" (Butler, 1993, p. 333). Es así como la persona travestida produce una imagen unificada de mujer y al mismo tiempo abre el debate sobre el ser mujer más allá del vestir. "Al imitar el género, la travestida manifiesta de forma implícita la estructura imitativa del género" (Butler, 2007, p. 269). La sociedad heteropatriarcal niega periferias donde existe un tercer sexo, "en el que se incluirían todas 
las personas que transgreden el género, incluso los hombres que transgreden estereotipos tradicionalmente considerados como masculinos" (Carrera, Fernández y Rodríguez, 2013, p. 48).

Al indagar sobre el Carnaval de Cádiz se comprendió la intención de los asistentes para participar, pues ha sido un escenario para reivindicar la igualdad, justicia y fraternidad. "Cuando se habla de carnaval se destaca la función liberadora, en lo social y psicológico, que tiene la fiesta" (Marchena, 2013, p. 77). Los datos hallados en fuentes bibliográficas, contrastados con nueve entrevistas a personas que han participado activamente, afirman la necesidad de espacios culturales y carnavaleros, para entrar al pueblo en aires de receso a la monotonía del sistema hegemónico. La fiesta es parte de la cultura popular, libera tensiones y remite a encuentros más fraternos y libertarios.

La ruptura de la norma hegemónica y la consolidación de las nuevas masculinidades apuntan a "sociedades más justas donde todas y todos estén cómodos independientemente del sexo. Las nuevas masculinidades deben crear horizontes para la igualdad" (Sanfélix, 2012. p. 245). Los hombres fotografiados eran conscientes de normas rígidas que prohíben vestir y actuar, pero era carnaval, así que decidieron teatralizar, sentir la vida cómica popular. Así se demuestra que las configuraciones culturales del sexo y el género podrían entonces multiplicarse, cuestionarse y representarse de diversas maneras, "derrocando el propio binarismo del sexo y revelando su antinaturalidad fundamental" (Butler, 2007, p. 288).

Aún hay mucho por descubrir, pues este aporte sólo fue para explorar, cuestionar, reconfigurar normas, resaltar propuestas descolonizadoras y creer en los escenarios de libertad. Todos los entrevistados aseguraron que en la cotidianidad no podrían actuar de la misma manera, pues "no ser reconocido socialmente como un heterosexual real es perder una identidad social posible y quizá lograr otra que esté mucho menos castigada" (Butler, 2017, p. 170). Por eso se siguen cuestionando las miradas de las culturas hegemónicas, que muchas veces señalan a las personas travestidas como enfermos y recurren a tratamientos psiquiátricos que condenan. Desaprender el género es necesario y constituye un desafío, "pues sólo formando y sensibilizando a las futuras generaciones educadores y educadoras en estas temáticas, podremos garantizar su tarea como verdaderos agentes subversivos al servicio de la liberación y de la justicia social (Carrera, 2016, p. 11). El amor propio y al prójimo es la excusa para liberar mentes y motivar a la emancipación de los cuerpos y sentidos en la construcción de un mundo justo y sin censura.

\section{Referencias}

Bajtín, M. (2003). La Cultura Popular en la Edad Media y el Renacimiento. Moscú: Alianza Editorial.

Bajtín, M. (1990). La cultura popular en la Edad Media y en el contexto de Rabelais. Madrid: Alianza.

Baroja, J. C. (1979). El carnaval. Análisis histórico - cultural. Madrid: Taurus.

Bonilla, E. y Rodríguez, P. (1995). Más allá del dilema de los métodos. Bogotá: Norma

Bouteldja, H. (2013). Ustedes, los blancos. Instituto para el Diálogo Global, 253 - 263. 
Butler, J. (1993). Cuerpos que importan. Sobre los límites materiales y discursivos del sexo. Barcelona: Paidós.

Butler, J. (2007). El Género en Disputa. El feminismo y la subversión de la identidad. España: Paidós.

Butler, J. (2017). Cuerpos aliados y lucha política. Barcelona: Paidós.

Carrera, V., Fernández, M., \& Rodriguez, Y. (2013). Heteronormatividad, Cultura y Educación. InterseXiones, 45 - 76.

Carrera, M., Lamerias, M., Xosé , M., Yolanda, R., \& Patricia, A. (2016 ). De las tecnologías de la subversión, un desafío pedagógico para la educación social. Revista de educación social

Carrigan, T., Connell, B., \& Lee, J. (1987 [1985]). “Toward a new sociology of masculinity”, en H. BROD (comp.), The making of masculinities. The new men's studies, Boston, Unwin \& Hyman.

Chisholm, C. (1970). Unbought and unbossed. New York: Hamington Company

Cook, R., \& Cusack, S. (2009). Estereotipos del género. Pensilvania: University of Pennsylvania.

De Alba, M. (2010). La imagen como método en la construcción de significados sociales. Iztapalapa, Revista de Ciencias Sociales y Humanidades. 69, 41-65.

Dewey, J. (2008). El arte como experiencia. Barcelona: Paidós.

Fernández, E. (2016). El potencial comunicativo de las chirigotas gaditanas y su realización televisiva. Sevilla: Universidad de Sevilla.

Ferreiro, A. (2012). Una Mirada a la Investigación Cualitativa desde las artes. Revista de Artes y Humanidades, 2(4), $01-24$.

Fonseca, C., \& Quintero, M. (2009). La Teoría Queer: la de-construcción de las sexualidades periféricas. Sociológica, 43 - 60.

García, R. (2013). La carnavalización del mundo como crítica: risa, acción política y subjetividad en la vida social y en el hablar. Athenea Digital , 121 - 130.

Gómez, A. (2013). Elementos metodológicos para el análisis de imágenes . Universidad Central de Catalunya, 346 - 354.

González, T. (2008). El papel de la fotografía en la investigación cualitativa. En C. Ibero, El ser enfermero (págs. 04 - 11). Buenos Aires: Salud Colectiva.

González, A. (2009). Michel Foucault, Judith Butler, y los cuerpos e identidades críticas, subversivas y deconstructivas de la Intersexualidad. ISEGORÍA. Revista de Filosofía Moral y Política, 235 - 244.

Greene, E., Addams, J., y Hamiltong, A. (2003). Women at the hage: the international congress of women and its results. Illinois: Urbana and Chicago 
Jhonson, E. (2011). Un sueño de paz, la lucha de una mujer liberiana por cambiar su destino y el de su país. Madrid: Aguilar.

Kelly, P. (1984). Luchar por la esperanza: sin violencia hacia un futuro verde. Barcelona: editorial debate.

Lauteris, T. (2015). Género y Teoría Queer. Mora, 107 - 118.

Lugones, M. (2008). Género y Decolonialidad. Buenos Aires: Tabula Raza.

Marchena, P. (2013). Carnaval de Cádiz: Espacio, Tiempo y forma de una fiesta ancestral. Pensar en carnaval, $52-58$

Martínez, S., \& Aguero, J. (2017). La producción de conocimientos en Trabajo Social: hacia una decolonialidad del saber. Cuadernos de Trabajo Social, 297 - 308.

Mastriano, R. (2013). Identidad, Sexualidad y Transgresión en el carnaval de Barranquilla. Washington: Fairfax.

Menchu, R. (2002). Hacia una cultura de paz. Buenos Aires: Lumen.

Montiel, A. (2010). La influencia de las máscaras italianas en el Carnaval de Cádiz. Cádiz: Asociación de autores del Carnaval de Cádiz.

Oyèrónkẹ́ Oyěwùmí. (1997). The Invention of Women: Making an African Sense of Western Gender discourses. Minesota: New Edition

Parella, S. (2003). Mujer, inmigrante y trabajadora: la triple discriminación. Ed. Antrophos.

Peralta, C. (2009). Etnografía y Metodos Etnográficos. Revista Colombiana de Humanidades, 33-52.

Pérez, F. (2014). Identidad y diversidad cultural. Una visión antropológica del género y la sexualidad. RESED, 12 - 32.

Pisano, L. (2016). El Carnaval de los cuerpos. El desafío simbólico y político del transvestismo. Revista Internacional de Filosofía, 719-726.

Pla, I., Donat, A., \& Bernabeu, I. (2013). Estereotipos y prejuicios de género: factors determinantes en salud mental. Valencia : Universidad de Valencia .

Prat, J. (1990). El carnaval y sus rituales. Tarragona: Antropología Social.

Preciado, B. (2001). Manifiesto Contrasexual. Paidos, 42 - 47.

Sanfélix, J. (2012). Las nuevas masculinidades. los hombres frente al cambio en las mujeres. Prisma, revista de ciencias sociales, 7, 220-247.

Segarra, M. y Carabí, A. (eds.) (2000) Nuevas masculinidades. Barcelona: Icaria Editorial.

Sanmartín, R. (2000). La entrevista en el trabajo de campo. Revista de antropología social, 105-126.

Segato, R. (2016). La guerra contra las mujeres. Madrid: Mapas. 
Vasco, C. (1994). Tres estilos de trabajo en las ciencias sociales. Santafé de Bogotá: Cinep.

Voy a denunciar la agresión no por mí sino por los que sufren la homofobia toda su vida. (2017, 03 de Marzo). La voz del carnaval. https://n9.cl/gv6dx 